\title{
Periconceptional Folate Deficiency and Implications in Neural Tube Defects
}

\author{
J. Safi, ${ }^{1}$ L. Joyeux, ${ }^{2}$ and G. E. Chalouhi ${ }^{3}$ \\ ${ }^{1}$ Department of Obstetrics and Gynecology, St Joseph University, Hôtel-Dieu de France, 1100 Beirut, Lebanon \\ ${ }^{2}$ Department of Pediatric Surgery, Children's Hospital of Dijon, University Medical Center, 21000 Dijon, France \\ ${ }^{3}$ Department of Obstetrics and Fetal Medicine, Hôpital Necker-Enfants-Malades, Paris Descartes University, \\ Assistance Publique-Hôpitaux de Paris, 75015 Paris, France
}

Correspondence should be addressed to G. E. Chalouhi, gihad.chalouhi@gmail.com

Received 5 March 2012; Revised 3 May 2012; Accepted 4 June 2012

Academic Editor: Laura Murray-Kolb

Copyright () 2012 J. Safi et al. This is an open access article distributed under the Creative Commons Attribution License, which permits unrestricted use, distribution, and reproduction in any medium, provided the original work is properly cited.

\begin{abstract}
Nutritional deficiencies are preventable etiological and epigenetic factors causing congenital abnormalities, first cause of infant mortality. Folate deficiency has a well-established teratogenic effect, leading to an increasing risk of neural tube defects. This paper highlights the most recent medical literature about folate deficiency, be it maternal or paternal. It then focuses on associated deficiencies as nutritional deficiencies are multiple and interrelated. Observational and interventional studies have all been consistent with a $50-70 \%$ protective effect of adequate women consumption of folates on neural tube defects. Since strategies to modify women's dietary habits and vitamin use have achieved little progress, scientific as well as political effort is mandatory in order to implement global preventive public health strategies aimed at improving the alimentation of women in reproductive age, especially folic acid supplementation. Even with the recent breakthrough of fetal surgery for myelomeningocele, the emphasis should still be on prevention as the best practice rather than treatment of neural tube defects.
\end{abstract}

\section{Introduction}

Congenital abnormalities (CAs) concern all diseases of organs or body parts developed in utero. They can be either isolated localized in one organ or multiple affecting at least two organs grouped into a syndrome, a sequence, or an association. Their prevalence is about $14 \%$ of all human fetuses considering all types of abnormalities, that is, major (3\%) and minor (11\%), or lethal, severe, and benign [1]. Among major CAs, congenital heart diseases account for $25 \%$, limb defects for $20 \%$, and nervous system abnormalities for 10\% [2]. Moreover, CAs represent the first cause of infant mortalities, with an increasing proportion (more than $25 \%)$ in both developed and developing countries [1,3]. In 2002 in the USA, CAs caused $21 \%$ of infant deaths $[4,5]$. In the world, more than $10 \%$ of infant mortalities secondary to CA are caused by nervous system abnormalities [1].

Congenital abnormalities can develop at any time after the first month of pregnancy. From conception to birth, the human egg, then the embryo, and the fetus have to adapt, at a molecular and transcriptional level, to various changes in their cellular environment. At conception, this environment depends on the micronutritional status of maternal and paternal germ cells and after conception on maternal nutritional status, metabolism, and lifestyle. Maternal diet is the source of all the essential elements that will serve as basic components, transcriptional factors, growth factors, and messengers for embryological and fetal cells signaling and development.

Prevention of CAs is defined by individual and public health strategies that can reduce their prevalence. These active strategies include nutritional interventions, prevention of maternal infections and diseases, periconceptional care of sick mothers (epileptic or diabetic), control of professional and environmental exposure to teratogens, and special attention to pregnancies exposed to major health determinants such as obesity, tobacco, alcohol, and drugs [7].

One of the major breakthroughs in CA prevention has been the evidence that periconceptional folate supplementation can reduce the risk of neural tube defects (NTDs) [811] and other congenital abnormalities like cardiovascular malformations (CVMs), cleft lip and palate [12], urogenital 


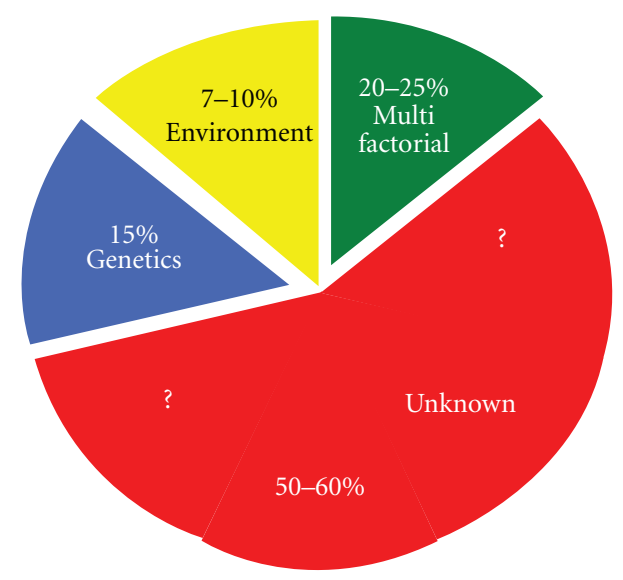

FIgURE 1: Causes of human congenital abnormalities (adapted from [6]).

abnormalities, and limb reductions [13]. It is essential to point out here that NTDs preventable through folate supplementation are isolated NTDs, and exclude other associated NTDs-grouped in syndrome, sequence, or association of CAs - which do not fall within the scope of this paper.

\section{Nutritional Deficiencies and Teratogenicity}

Congenital heart and central nervous system abnormalities encompass approximately 50\% (resp., 40 and 10\%) of the worldwide infantile deaths attributable to congenital abnormalities $[14,15]$. Major congenital anomalies are also a source of high morbidity, distress, and severe physical, psychological, and social handicaps [14].

Teratology, the science of the precise etiologies of CA, defines these causes as unknown in $50-60 \%$ of cases. The other etiologies are epigenetic and multifactorial in 20$25 \%$ of cases, chromosomic or genetic with a single gene mutation in almost $15 \%$ of cases, and epigenetic, acquired, and monofactorial under the influence of environmental factors (such as maternal sickness, infections, medications, ionizing radiations, and alcohol) in about $10 \%$ of cases [15] (Figure 1).

Clinical studies [3] have revealed that a specific teratogen can induce various malformations, or none, depending on the timing of exposure of the developing embryo. Thereby, each organ or system displays a critical, yet brief, window, considered as a phase of susceptibility to environmental teratogens. It is commonly known that the earlier the exposure, the more severe the abnormalities, which can even lead to death of the embryo during the first month postconceptionally. Most deleterious teratogens produce nonspecific congenital abnormalities such as general dysmorphic features, intrauterine demise, or intrauterine growth restriction, as well as specific CA, which can characterize a particular agent. Nevertheless, a specific CA can result from various environmental agents. For example, spina bifida occurrence is increased with three principal maternal risk factors and still exhibits the same clinical aspect: maternal valproic acid intake, insulin-dependent diabetes, and folate deficiency.

Improved comprehension of etiopathogenesis has led to the emerging evidence that equilibrating and optimizing maternal dietary intake can reduce the incidence of CA. Influence of nutrition on fetal development has been repeatedly proven, at the molecular as well as the clinical level. Very recently, pilot data from a randomized double blind controlled trial showed that periconceptional maternal micronutrient supplementation affected fetal genome methylation patterns in DNA samples drawn from cord blood [16]. Any nutritional imbalance can alter genotype expression and induce abnormal phenotype. This is the fundamental epigenetic gene/nutrients link.

\section{Characteristics of Folate Deficiency}

Folate, or vitamin B9, is most abundantly found in dark green leafy vegetables, but also in orange juice, legumes (e.g., black beans and kidney beans), nuts, asparagus, and strawberries. With the exception of liver, meat is not a good source of folate [17]. Folic acid is the synthetic form of folate and is usually more bioavailable than natural food folate. Due to its lower bioavailability from natural foods, many countries have adopted mandatory folic acid food fortification programs.

Folates are essential for the synthesis of thymidylate and purines, precursors required for de novo DNA synthesis and hence, cell division [22]. This feature is of particular importance in a rapidly dividing and developing embryo. Folate coenzymes are also implicated in amino acid metabolism (homocystein) and methylation. In order to be stored intracellularly, folate ought to be metabolized into tetrahydrofolate (THF) by methionine synthase, a B12dependent enzyme. In humans, the association of CA and folate deficiency began to be acknowledged in the 1950s, when Methotrexate was widely used for abortions. Moreover, Methotrexate and Aminopterin, both folic acid antagonists, were being used for the treatment of psoriasis and certain cancers in pregnant women, which resulted in CA, thus 


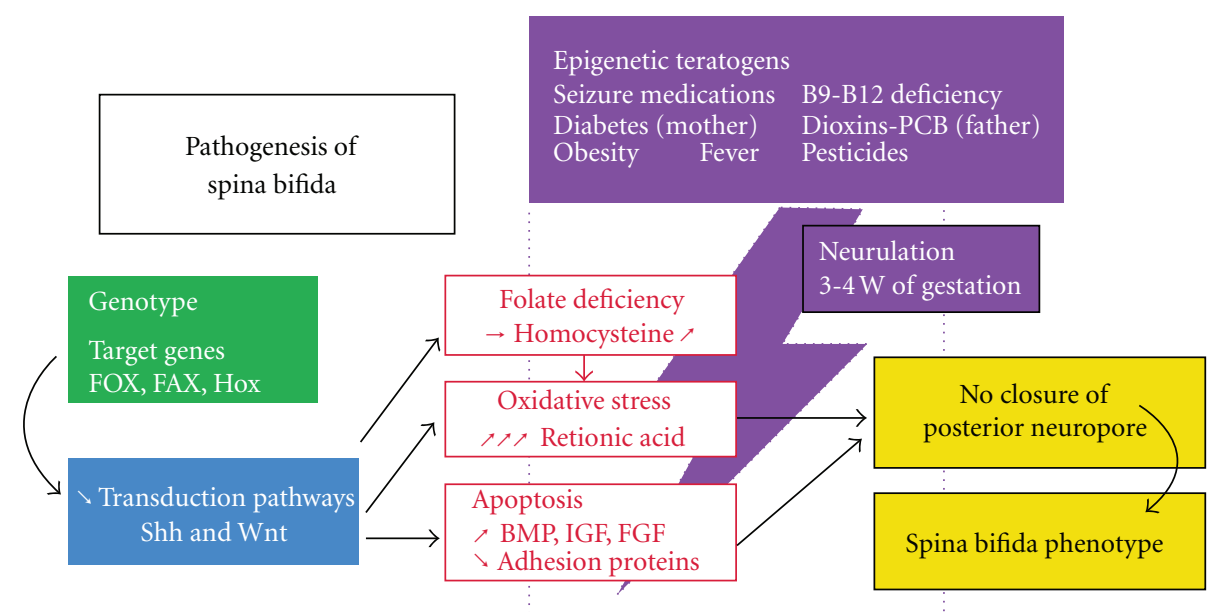

FIgure 2: Combined etiopathogenesis of spina bifida (Shh: sonic hedgehog, Wnt: Wnt ligand in Wnt/ $\beta$ catenin signaling pathway, BMP: bone morphogenic protein, IGF: insulin-like growth hormone, and W: weeks) [18].

Table 1: Proven and suspected risk factors for spina bifida $(\mathrm{NP}=$ not proven).

\begin{tabular}{lc}
\hline Risk factors: proven and certain & Relative risk \\
\hline History of NTD-affected pregnancy & 30 \\
Valproic acid and carbamazepine & $10-20$ \\
Pregestational maternal diabetes & $2-10$ \\
Inappropriate/deficient folic acid supplementation & $2-8$ \\
Paternal exposure to dioxins in Agent Orange [19] & 2 \\
\hline Risk factors: suspected & Relative risk \\
\hline Maternal vitamin B12 status & 3 \\
Maternal diarrhea & $3-4$ \\
Maternal obesity & $1.5-3.5$ \\
Maternal hyperthermia & 2 \\
\hline Nonproven (NP) risk factors, with & Relative risk \\
epidemiological associations & $\mathrm{NP}$ \\
Gestational diabetes & $\mathrm{NP}$ \\
Pesticides & $\mathrm{NP}$ \\
Herbicides & $\mathrm{NP}$ \\
Fumonisins & $\mathrm{NP}$ \\
Water chlorination & $\mathrm{NP}$ \\
Heavy metals: lead & $\mathrm{NP}$ \\
Organic solvents & $\mathrm{NP}$ \\
Plastic byproducts (vinyl chloride, PVC) & $\mathrm{NP}$ \\
Toxic waste sights & $\mathrm{NP}$ \\
Retinoic acid (vitamin A) excess [20, 21] & $\mathrm{NP}$ \\
\hline
\end{tabular}

starting to reveal an association. Additional research into neural tube defects and their etiologies was further facilitated by the advances in genetics and nonmendelian complex diseases, paving the way for the study of metabolism and transport of folate-homocysteine as potential risk factors for spina bifida. Since then, folic acid supplementation has remained one of the few interventions, if not the only, that can prevent major CA in the human fetus.

3.1. Maternal Folate Deficiency. During pregnancy, folate requirements increase to accommodate embryonic and fetal development and maternal tissue growth. While folate is actively transported to the fetus as demonstrated by higher cord blood folate concentrations relative to maternal blood [23], maternal serum and RBC concentrations of folate decline for several reasons [24-29]: increased demand, dilution secondary to increased intravascular volume, increased folate catabolism and clearance, decreased absorption, and inadequate intake $[24,27]$. Folate deficiency is known to lead to maternal megaloblastic anemia, which may be fatal if left untreated [30].

3.1.1. Prevention of NTDs. Addressing folate deficiency as it relates to NTDs occurrence or recurrence has been the subject of considerable study. The evidence in public health that daily folic acid supplementation (alone or in combination with other vitamins and minerals) has a significant protective effect in preventing NTDs, that is, anencephaly and spina bifida as well as cardiovascular malformations is now overwhelming [31]. There is also a significant reduction in risk of recurrence, while prevention of other birth defects (cleft palate cleft lip) and or miscarriages was not proven to be statistically significant. The controversy about the potential role played by folic acid supplementation in the rising colon cancer rates should no longer be defended, as the majority of the evidence available is reassuring [30].

The current identified maternal risk factors for NTDs include four established factors: personal or familial past history of NTD (relative risk RR of 30), maternal diabetes (RR, 2-10), certain antiseizure medications (carbamazepine and valproic acid, with RR of 10 to 20), and maternal folate deficiency (RR, 2-8) [32] (Table 1 and Figure 2). Maternal factors such as obesity, hyperthermia, race, ethnicity, smoking, alcohol abuse, malabsorption, intestinal disease, and 
liver or renal failure, can also contribute to genesis of NTDs either directly or indirectly by folate deficiency [30, 33]. Low folate intake, in addition to inadequate absorption of food folate and further loss through cooking practices, leaves the majority of women of reproductive age deficient in folates. As closure of the developing neural tube occurs by the 28th postconceptional day, that is, the 42 nd gestational day, before the majority of women are aware of their pregnancy, this precludes the efficacy of folic acid given after the diagnosis of pregnancy.

Based on current evidence, it is recommended that all women of childbearing age receive $0.4 \mathrm{mg}(400 \mu \mathrm{g})$ of folic acid daily periconceptionally ( 1 month before and 2 months after). Women at high risk for NTDs, that is, women with previous NTD-affected pregnancy, obesity (BMI > 30), diabetes, and epilepsy, should receive 4 to $5 \mathrm{mg}$ of folic acid daily preconceptionally, starting at least one month before conception and continuing throughout the first trimester of pregnancy [30]. The recommended dose of $4 \mathrm{mg} / \mathrm{d}$ was chosen for a Medical Research Council trial that resulted in a $72 \%$ reduction in NTD recurrence $[17,34]$. The adequate blood folate concentration and minimum supplemental dose shown to be effective for the prevention of NTDs are not precisely known. The only Randomized Controlled Trial (RCT) showing reduction in occurrence of NTDs used an $800 \mu \mathrm{g} / \mathrm{d}$ dose, whereas other intervention trials studying occurrence or case control studies of recurrence used a $400 \mu \mathrm{g} / \mathrm{d}$ dose. All of the studies demonstrated significant reduction of NTDs [9, 11, 35]. However, the NTD risk reduction with higher blood folate concentrations is well documented, as is the enhancement of folate status with the combined consumption of folic acid supplements or fortified foods and a healthy diet containing natural folate [36-38].

Proper evidence on folate dose remains limited. For instance, the precise red blood cell folate concentration of $906 \mathrm{nmol} / \mathrm{L}$ was demonstrated to be related to a lowest risk of NTDs in the offspring. This concentration was not reached within four weeks of the currently recommended supplementation, according to Daly et al. [37]. However, Brämswig et al. were able to reach that same target level within four weeks of supplementation with a daily intake of $800 \mu \mathrm{g} / \mathrm{d}$ folic acid. These results suggest the need for the reevaluation of the current dosage recommendation of folic acid supplementation with respect to NTD prevention [39].

3.1.2. Prevention of Cardiovascular Malformations (CVMs). Although the preventive efficacy of NTDs by folic acidcontaining multivitamins (MV) or folic acid alone has been well established and demonstrated to be better than any other CA prevention, the available data also supports the essential role of folic acid for normal fetal cardiac development during early embryogenesis. The combination of the results of two Hungarian intervention trials [40,41] (OR with 95\% CI: $0.57,0.39-0.85)$ showed a $43 \%$ risk reduction of cardiovascular malformations after MV supplementation.

Two more recent population-based observational studies demonstrated a significant reduction in the rates of CVM with folic acid intake [42, 43]. Furthermore, a significant reduction in the birth prevalence of severe CVMs was reported in Quebec, Canada, after folic acid fortification of grain products [44]. Another Canadian study, a systematic review and meta-analysis by Goh et al., concluded that maternal consumption of MV was associated with decreased risk for several congenital anomalies (OR 0.78, 95\% CI 0.670.92 in case control studies and OR $0.61,95 \%$ CI $0.40-0.92$ in cohort and randomized controlled studies for cardiovascular defects) [45].

In conclusion, the available evidence concerning CVMs shows that any public health action of CA prevention with periconceptional MV or folic acid supplementation should necessarily take into consideration CVMs, with regard not only to demonstrated efficacy but also to the more elevated prevalence of CVM as compared to NTD or other defects, and thus to the superior absolute number of preventable cases of CVM per 100,000 births. This should be particularly true in countries with a low NTD prevalence, and a low NTD: CVM ratio, such as the USA.

3.2. Paternal Folate Deficiency. Teratogenicity may exist at the conceptional level as well at the preconceptional level, thus affecting both maternal and paternal gametes. A recent proven example, although it has not been fully elucidated, is the effect of paternal exposure to dioxins. A statistically significant causal link has been demonstrated between dioxin exposure and spermatozoid folate deficiency leading to spina bifida $[19,46,47]$.

The chemical name for dioxin is 2,3,7,8-tetrachlorodibenzo-para-dioxin (TCDD). The media term "dioxins" is often used for a family of structurally and chemically related products. Dioxins are mainly unwanted byproducts of a wide range of industrial processes. In terms of dioxin release into the environment, uncontrolled waste incinerators (solid waste and hospital waste) are often the worst culprits, due to incomplete burning. Although formation is local, environmental distribution is global. Dioxins accumulate throughout the food chain, with increasing concentrations. The highest levels of these compounds are found in some soils, sediments, and food, especially dairy products, meat, fish, and poultry. Once the human body has absorbed dioxins, they persist for a long time because of their chemical stability and their ability to accumulate in fat tissue.

After preconceptional exposure to dioxins, the risk of mutations in spermatozoids is significantly increased, leading to an increased risk of spina bifida [19, 46, 47] through mechanisms involving folate deficiency [48]. In animal models, the teratogenic and mutagenic effect of Dioxin has been extensively proven, while light had just started to be shed on the mechanism by which human paternal Dioxin exposure can lead to congenital abnormalities. The causative and statistically significant association between the Dioxin containing Agent Orange, which was used in the Vietnam War, and spina bifida, is irrefutable [19, 46, 47]. Precise biological mechanisms of exposure to Dioxin are epigenetic, based on activation of the AhR/ARNT (aryl hydrocarbon receptor/aryl hydrocarbon receptor nuclear translocator) 
complex of spermatogenesis, leading to folate deficiency as the cause of NTD phenotype [48, 49]. This complex is widely distributed, but is particularly abundant in the human testicle, which renders it one of the most sensitive organs to Dioxins. This explains its direct interference with human spermatogenesis and male fertility [50]. Halwachs et al. have recently demonstrated that dioxins deregulate the AhR signaling pathway [48]. This effect is mediated by a downregulation of Rfc 1 (reduced folate carrier 1) gene expression and reduced carrier protein levels. This downregulation by TCDD was shown to be time- and dosedependent in rat livers and resulted in functional folate deficiency in male and female cells and tissues, including germ cells [48].

In summary, dioxins are diffusely distributed in the environment and tend to accumulate along the food chain. Chronic consumption of contaminated food can lead to deregulation of genetic mechanisms implicated in folate homeostasis. Consequently, widespread folate deficiency in men and women, generally due to inadequate consumption of alimentary folates, can be increased. The final consequences are NTDs in fetuses born to mothers, but also fathers, deficient in intracellular folate concentration in germ cells. Paternal folate deficiency could be one of the factors explaining the incomplete success of recommended folate supplementation to prevent NTDs.

\subsection{Associated Deficiencies}

3.3.1. Vitamin B12. Vitamin B12 (cobalamin) is a pivotal cofactor for key enzyme reactions including the generation of methionine and tetrahydrofolate. This vitamin is found almost exclusively in foods of animal origin (meats, dairy products). Although inadequate vitamin B12 status is thought to be limited to the aging population, it has been found with a relatively high prevalence in women of reproductive age with restricted consumption of animalbased food, an increasingly popular dietary trend [17], and in pregnant women who are more likely to be deficient than nonpregnant women [51].

Vitamin B12 deficiency may impair folate metabolism through impairment of methionine synthase enzyme. It has been associated with NTDs in a number of studies. Ray and Blom identified 17 NTD case-control studies related to B12 status, with an overall reported trend towards lower mean B12 concentration in mothers with NTDaffected pregnancies [52]. The two largest positive studies conducted after the introduction of folate fortification in the United States and Canada $[53,54]$ showed that the risk of NTDs was inversely proportional to the measured serum concentrations of vitamin B12 (holotranscobalamin). Furthermore, in Ireland, risk of NTDs was strongly positively correlated to low B12 status in a population not exposed to folic acid fortification or supplements $[55,56]$. Kirke et al. uncovered a fivefold increase in NTD risk for women in the lower quartile of associated folate and B12 deficiencies, compared to half this rate for only folate deficiency, thus demonstrating the synergistic actions of both vitamins. More recently, Zhang et al. [57] and Molloy et al. [56] reported higher NTD risk in mothers within the lowest quartile for B12 concentrations, with an approximate three-fold increase. Both Kirke and Zhang demonstrated that B12 and folate were two independent risk factors. In 2009, the National Institutes of Health validated the results of Molloy et al., and concluded that improving B12 status in women of childbearing age would prevent NTDs. The recommended daily Vitamin B12 allowance for pregnant women is $2.6 \mu \mathrm{g} / \mathrm{day}[17,58]$.

Caregivers should be aware that high levels of folic acid intake (tolerable upper intake level from fortified foods or supplements is $1000 \mu \mathrm{g} / \mathrm{d}$ for adults), can mask vitamin B12 deficiency, resulting in permanent nerve damage, especially in elderly individuals [30].

3.3.2. Other Deficiencies. As previously mentioned, the etiology of CA is multifactorial, and most factors are still unknown. Toxic chemicals are detected everywhere, in the dietary products of the general population [59], in the inhaled air [60], and even in neonates' cord blood [61]. According to a WHO report in 2010 [62], the top three most common groups of etiologies for CA in developed countries are epigenetic: maternal diseases (diabetes and hyperthermia), pathologic maternal deficiencies (folate and iodine deficiency), and exposure to teratogens (medications, drugs including tobacco and alcohol, environmental chemicals like pesticides, and ionizing radiations).

The unfolding of new associations between malnutrition and diseases has made it clear that women in their reproductive years have multiple complex nutritional deficiencies; this might also be true for the general population. Recent studies showed that prenatal multimicronutrient supplementation was associated with a significantly reduced risk of low birth weight when compared with iron-folic acid supplementation $[63,64]$. Moreover, Chen et al. proved that periconceptional multivitamin supplementation containing folic acidtwo months before conception and until completion of the second month-containing folic acid can prevent the occurrence of NTDs [65]. These maternal and paternal nutritional deficiencies are probably multicausal. They can be due to digestive malabsorption, but also to excessive cooking of fresh food that destroys most of the vitamins, and to widespread consumption of industrial food products. Future policies should be directed towards improving food quality.

\section{Prenatal Management of NTDs}

4.1. Prevention: Current Strategies and Their Benefits. Epidemiological studies, both observational and interventional, have all been consistent with a 50 to $70 \%$ protective effect of adequate consumption of folates on NTDs [66]. Since strategies to modify women's dietary habits and vitamin use have achieved little progress [67] and since about half of all the pregnancies are unplanned, maternal supplementation alone cannot be an effective approach. Only maintenance of optimal nutritional status throughout the reproductive years will help ensure normal fetal development [17]. 
TABLE 2: MOM study results, January 2011 [68].

\begin{tabular}{lccc}
\hline Results (\%) & $\begin{array}{c}\text { Prenatal } \\
\text { surgery }\end{array}$ & $\begin{array}{c}\text { Postnatal } \\
\text { surgery }\end{array}$ & $\begin{array}{c}P \\
\text { value }\end{array}$ \\
\hline $\begin{array}{l}\text { At } 12 \text { months } \\
\quad \text { Shunt placement }\end{array}$ & 40 & 82 & $<0.001$ \\
$\quad$ Hindbrain herniation & 64 & 96 & $<0.001$ \\
$\begin{array}{l}\text { At } 30 \text { months } \\
\quad \begin{array}{l}\text { Psychomotor development } \\
\quad \text { Bayley index mean) }\end{array}\end{array}$ & 64 & 58,3 & 0.03 \\
$\quad \begin{array}{l}\text { Motor function \& independent } \\
\text { walking on examination }\end{array}$ & 42 & 21 & 0.01 \\
\hline
\end{tabular}

Starting in North America, fortification of food with folic acid has made folic acid accessible to all men and women of childbearing age without necessitating behavioral change and has proven to be both efficient and more homogeneous [33]. An additional rationale for fortification is that, in contrast with food folate, bioavailability of folic acid from fortified food is $85 \%$ (it is a $100 \%$ from vitamin supplement) [30]. In 1992, the US Public Health Service (USPHS) recommended that all women in their reproductive years consume $400 \mu \mathrm{g}$ of folic acid daily for prevention of NTDs. By 1998, and following Food and Drug Administration (FDA) regulations, all standardized enriched cereal grain products sold in the United States included $140 \mu \mathrm{g}$ folic acid/100 g. Folic acid was also added to breakfast cereals, corn grits, infant formulas, medical foods, and foods for special dietary use. In 2009, the US Preventive Services Task Force published updated grade A recommendations reinforcing these guidelines [69]. By 2007, over 50 countries had implemented their own folic acid flour fortification programs, including Canada, Costa Rica, Chile, Australia, New Zealand, South Africa, and some Middle Eastern countries [70]. In the USA, the National Birth Defects Prevention Network reported a $36 \%$ decrease in the prevalence of NTDs, from 10.8 per 10,000 population during 1995-1996 to 6.9 at the end of 2006 [71]. In Europe, EUROCAT registries reported a 10\% decrease, from 10.5 per 10,000 in 2004 to 9.4 in 2008 [72]. A greater decline in NTDs was predicted [73], raising the question of what additional measures should be undertaken. According to the CDC 2010 report, disparities still exist among diverse ethnicities, as well as on a global worldwide basis. As current fortification programs only prevent about $9 \%$ of total annual cases of NTDs, an international public health solution is to expand the number of countries with mandatory fortification programs that have the potential to safely diminish the fraction of folic acid-preventable NTDs [74].

However, while the abundant literature depicts mandatory fortification programs as massive public health success stories [75], one study found that neither periconceptional supplementation nor dietary folic acid intake reduced the risk of NTDs, including spina bifida [76]. Moreover, another confirmed the protective effect of dietary folic acid alone, regardless of supplementation status, which did not appear to offer further benefit in reducing the risk of spina-bifidaaffected pregnancies, even among women with very low dietary folic acid consumption [77]. It is worth mentioning here that these were case-control studies that relied on selfreported maternal questionnaires, which raises the question of reporting accuracy, in the era of global awareness of the protective effect of folic acid. Furthermore, despite folic acid fortification and maternal supplementation, the incidence of NTDs has stabilized in the United States [33] and many other countries [78].

All this knowledge highlights the need for paired management strategy: prevention by folic acid and vitamin B12 maternal and paternal supplementations associated with a decreased exposure to the multiple risk factors and treatment such as fetal surgery.

4.2. Fetal Surgery. The first prenatal myelomeningocele (MMC) repair was performed in 1994 by Bruner and Tulipan endoscopically on 4 cases. Due to premature labor and birth, this technique was considered dangerous and unsatisfactory and was abandoned [79]. In 1997, the first cases of open MMC repair by hysterotomy were realized $[80,81]$.

Very recently, Adzick et al. proved, in the Management of Myelomeningocele Study (MOMS), the efficacy of fetal MMC surgery as compared to standard postnatal repair [68]. Prenatal surgery resulted in significant reduction of hindbrain herniation (Chiari II malformation), a reduction in need for shunting to relieve hydrocephalus, as well as improvements in motor function and mental development at 30 months (Table 2) $[68,82]$. However, preterm delivery and obstetrical complications were increased.

\section{Conclusion}

The etiologies of congenital abnormalities lie in epigenetics in the vast majority of cases. They are multifactorial, maternal as well as paternal, but universally associated with environmental teratogens. Future research and multicentric, large-scale trials should be directed to epigenetic profiling of congenital diseases, including neural tube defects.

Nutritional deficiencies are multiple, interrelated, and concern both men and women. Scientific as well as political effort is mandatory in order to implement global preventive public health strategies using fortification and supplementation.

\section{References}

[1] A. Rosano, L. D. Botto, B. Botting, and P. Mastroiacovo, "Infant mortality and congenital anomalies from 1950 to 1994: an international perspective," Journal of Epidemiology and Community Health, vol. 54, no. 9, pp. 660-666, 2000.

[2] EUROCAT, "Surveillance of Congenital Anomalies in Europe, 1980-1999," E.S.o.C.A. EUROCAT, European surveillance of congenital anomalies: University of Ulster, Newtownabbey, Northern Ireland, 2002.

[3] A. Correa-Villaseñor, J. Cragan, J. Kucik, L. O’Leary, C. Siffel, and L. Williams, "The metropolitan atlanta congenital defects program: 35 years of birth defects surveillance at the centers 
for disease control and prevention," Birth Defects Research Part A, vol. 67, no. 9, pp. 617-624, 2003.

[4] J. Petrini, K. Damus, R. Russell, K. Poschman, M. J. Davidoff, and D. Mattison, "Contribution of birth defects to infant mortality in the United States," Teratology, vol. 66, no. 1, supplement, pp. S3-S6, 2002.

[5] CDC, "Periconceptional use of multivitamins and the occurrence of anencephaly and spina bifida," Morbidity and Mortality Weekly Report, vol. 37, no. 47, pp. 727-730, 1988.

[6] K. L. Moore and T. V. N. Persaud, The Developing Human: Clinically Oriented Embryology, Saunders, Philadelphia, $\mathrm{Pa}$, USA, 2003.

[7] H. Dolk, "What is the "primary" prevention of congenital anomalies?” The Lancet, vol. 374, no. 9687, p. 378, 2009.

[8] K. M. Laurence, N. James, M. Miller, and H. Campbell, "Increased risk of recurrence of pregnancies complicated by fetal neural tube defects in mothers receiving poor diets, and possible benefit of dietary counselling," British Medical Journal, vol. 281, no. 6255, pp. 1592-1594, 1980.

[9] R. W. Smithells, S. Sheppard, and C. J. Schorah, "Possible prevention of neural-tube defects by periconceptional vitamin supplementation," Lancet, vol. 1, no. 8164, pp. 339-340, 1980.

[10] N. Wald, J. Sneddon, J. Densem, C. Frost, and R. Stone, "Prevention of neural tube defects: results of the medical research council vitamin study," Lancet, vol. 338, no. 8760, pp. 131-137, 1991.

[11] A. E. Czeizel and I. Dudas, "Prevention of the first occurrence of neural-tube defects by periconceptional vitamin supplementation," New England Journal of Medicine, vol. 327, no. 26, pp. 1832-1835, 1992.

[12] M. Tolarova, "Periconceptional supplementation with vitamins and folic acid to prevent recurrence of cleft lip," Lancet, vol. 2, no. 8291, p. 217, 1982.

[13] A. E. Czeizel, "Reduction of urinary tract and cardiovascular defects by periconceptional multivitamin supplementation," American Journal of Medical Genetics, vol. 62, no. 2, pp. 179$183,1996$.

[14] EUROCAT, "Surveillance of Congenital Anomalies in Europe, 1980-1999,” E.S.o.C.A. EUROCAT, European surveillance of congenital anomalies, University of Ulster, Newtownabbey, Northern Ireland, 2002.

[15] EUROCAT, "A Review of Environmental Risk Factors for Congenital Anomalies," E.S.o.C.A. EUROCAT, EUROCAT, European surveillance of congenital anomalies, University of Ulster, Newtownabbey, Northern Ireland, 2004.

[16] B. Khulan, W. N. Cooper, B. M. Skinner et al., "Periconceptional maternal micronutrient supplementation is associated with widespread gender related changes in the epigenome: a study of a unique resource in the Gambia," Human Molecular Genetics, vol. 21, no. 9, pp. 2086-2101, 2012.

[17] J. L. Simpson, L. B. Bailey, K. Pietrzik, B. Shane, and W. Holzgreve, "Micronutrients and women of reproductive potential: required dietary intake and consequences of dietary deficiency or excess. Part i Folate, Vitamin B12, Vitamin B6," Journal of Maternal-Fetal and Neonatal Medicine, vol. 23, no. 12, pp. 1323-1343, 2010.

[18] L. Joyeux, Etiopathogenesis and treatment of for congenital malformations curable in utero [medical thesis], p. 196, June 2011.

[19] A. D. Ngo, R. Taylor, and C. L. Roberts, "Paternal exposure to Agent Orange and spina bifida: a meta-analysis," European Journal of Epidemiology, vol. 25, no. 1, pp. 37-44, 2010.

[20] E. Danzer, U. Schwarz, S. Wehrli, A. Radu, N. S. Adzick, and A. W. Flake, "Retinoic acid induced myelomeningocele in fetal rats: characterization by histopathological analysis and magnetic resonance imaging," Experimental Neurology, vol. 194, no. 2, pp. 467-475, 2005.

[21] E. Danzer, A. Radu, L. E. Robinson, M. V. Volpe, N. S. Adzick, and A. W. Flake, "Morphologic analysis of the neuromuscular development of the anorectal unit in fetal rats with retinoic acid induced myelomeningocele," Neuroscience Letters, vol. 430, no. 2, pp. 157-162, 2008.

[22] L. B. Bailey, "Folic acid," in Handbook of Vitamins, J. Zempleni, D. B. McCormick, and J. W. Suttie, Eds., p. 387, CRC Press, Taylor \& Francis Group, Boca Raton, Fla, USA, 2007.

[23] J. Ek, "Plasma and red cell folate values in newborn infants and their mothers in relation to gestational age," Journal of Pediatrics, vol. 97, no. 2, pp. 288-292, 1980.

[24] I. Chanarin, The Megaloblastic Anaemias, Blackwell, London, UK, 1969.

[25] H. W. Bruinse, V. H. D. Berg, and A. A. Haspels, "Maternal serum folacin levels during and after normal pregnancy," European Journal of Obstetrics Gynecology and Reproductive Biology, vol. 20, no. 3, pp. 153-158, 1985.

[26] I. Qvist, M. Abdulla, M. Jagerstad, and S. Svensson, "Iron, zinc and folate status during pregnancy and two months after delivery," Acta Obstetricia et Gynecologica Scandinavica, vol. 65, no. 1, pp. 15-22, 1986.

[27] T. Tamura and M. F. Picciano, "Folate and human reproduction," American Journal of Clinical Nutrition, vol. 83, no. 5, pp. 993-1016, 2006.

[28] H. Takimoto, N. Mito, K. Umegaki et al., "Relationship between dietary folate intakes, maternal plasma total homocysteine and B-vitamins during pregnancy and fetal growth in Japan," European Journal of Nutrition, vol. 46, no. 5, pp. 300306, 2007.

[29] J. M. W. Wallace, M. P. Bonham, J. J. Strain et al., "Homocysteine concentration, related $\mathrm{B}$ vitamins, and betaine in pregnant women recruited to the Seychelles Child Development Study," American Journal of Clinical Nutrition, vol. 87, no. 2, pp. 391-397, 2008.

[30] V. S. Talaulikar and S. Arulkumaran, "Folic acid in obstetric practice: a review," Obstetrical and Gynecological Survey, vol. 66, no. 4, pp. 240-247, 2011.

[31] L. M. De Regil, A. C. Fernández-Gaxiola, T. Dowswell, and J. P. Peña-Rosas, "Effects and safety of periconceptional folate supplementation for preventing birth defects," Cochrane Database of Systematic Reviews, no. 3, Article ID CD007950, 2009.

[32] L. E. Mitchell, N. Scott Adzick, J. Melchionne, P. S. Pasquariello, L. N. Sutton, and A. S. Whitehead, "Spina bifida," Lancet, vol. 364, no. 9448, pp. 1885-1895, 2004.

[33] CDC, "CDC grand rounds: additional opportunities to prevent neural tube defects with folic acid fortification," Morbidity and Mortality Weekly Report, vol. 59, no. 31, pp. 980-984, 2010.

[34] N. Wald, J. Sneddon, J. Densem, C. Frost, and R. Stone, "Prevention of neural tube defects: results of the medical research council vitamin study," Lancet, vol. 338, no. 8760, pp. 131-137, 1991.

[35] R. J. Berry, Z. Li, J. D. Erickson et al., "Prevention of neuraltube defects with folic acid in China," New England Journal of Medicine, vol. 341, no. 20, pp. 1485-1490, 1999.

[36] G. P. A. Kauwell, Q. Yang, and L. B Bailey, "Folate: recommended intakes, consumption, and status," in Folate in Health 
and Disease, L. B Bailey, Ed., pp. 467-490, CRC Press, Taylor and Francis Group, Boca Raton, Fla, USA, 2009.

[37] L. E. Daly, P. N. Kirke, A. Molloy, D. G. Weir, and J. M. Scott, "Folate levels and neural tube defects: implications for prevention," Journal of the American Medical Association, vol. 274, no. 21, pp. 1698-1702, 1995.

[38] G. J. Cuskelly, H. McNulty, and J. M. Scott, "Effect of increasing dietary folate on red-cell folate: implications for prevention of neural tube defects," Lancet, vol. 347, no. 9002, pp. 657-659, 1996.

[39] S. Brämswig, R. Prinz-Langenohl, Y. Lamers et al., "Supplementation with a multivitamin containing $800 \mu \mathrm{g}$ of folic acid shortens the time to reach the preventive red blood cell folate concentration in healthy women," International Journal for Vitamin and Nutrition Research, vol. 79, no. 2, pp. 61-70, 2009.

[40] A. E. Czeizel, "Periconceptional folic acid containing multivitamin supplementation," European Journal of Obstetrics Gynecology and Reproductive Biology, vol. 78, no. 2, pp. 151161, 1998.

[41] A. E. Czeizel, M. Dobó, and P. Vargha, "Hungarian cohortcontrolled trial of periconceptional multivitamin supplementation shows a reduction in certain congenital abnormalities," Birth Defects Research Part A, vol. 70, no. 11, pp. 853-861, 2004.

[42] L. D. Botto, J. Mulinare, and J. D. Erickson, "Occurrence of congenital heart defects in relation to maternal multivitamin use," American Journal of Epidemiology, vol. 151, no. 9, pp. 878-884, 2000.

[43] I. M. Van Beynum, L. Kapusta, M. K. Bakker, M. Den Heijer, H. J. Blom, and H. E. K. De Walle, "Protective effect of periconceptional folic acid supplements on the risk of congenital heart defects: a registry-based case-control study in the northern Netherlands," European Heart Journal, vol. 31, no. 4, pp. 464-471, 2010.

[44] R. Ionescu-Ittu, A. J. Marelli, A. S. Mackie, and L. Pilote, "Prevalence of severe congenital heart disease after folic acid fortification of grain products: time trend analysis in Quebec, Canada," British Medical Journal, vol. 338, p. b1673, 2009.

[45] Y. I. Goh, E. Bollano, T. R. Einarson, and G. Koren, "Prenatal multivitamin supplementation and rates of congenital anomalies: a meta-analysis," Journal of Obstetrics and Gynaecology Canada, vol. 28, no. 8, pp. 680-689, 2006.

[46] M. C. Hatch and Z. A. Stein, "Agent Orange and risks to reproduction: the limits of epidemiology," Teratogenesis Carcinogenesis and Mutagenesis, vol. 7, no. 4, pp. 423-424, 1987.

[47] A. K. Giri, "Mutagenic and genotoxic effects of 2,3,7,8tetrachlorodibenzo-p-dioxin. A review," Mutation Research, vol. 168, no. 3, pp. 241-248, 1986.

[48] S. Halwachs, C. Lakoma, R. Gebhardt, I. Schäfer, P. Seibel, and W. Honscha, "Dioxin mediates downregulation of the reduced folate carrier transport activity via the arylhydrocarbon receptor signalling pathway," Toxicology and Applied Pharmacology, vol. 246, no. 1-2, pp. 100-106, 2010.

[49] D. A. Hansen, "Paternal environmental exposures and gene expression during spermatogenesis: research review to research framework," Birth Defects Research Part C, vol. 84, no. 2, pp. 155-163, 2008.

[50] R. Schultz, J. Suominen, T. Värre et al., "Expression of aryl hydrocarbon receptor and aryl hydrocarbon receptor nuclear translocator messenger ribonucleic acids and proteins in rat and human testis," Endocrinology, vol. 144, no. 3, pp. 767-776, 2003.

[51] J. G. Ray, J. Goodman, P. R. A. O’Mahoney, M. M. Mamdani, and D. Jiang, "High rate of maternal vitamin B12 deficiency nearly a decade after Canadian folic acid flour fortification," QJM, vol. 101, no. 6, pp. 475-477, 2008.

[52] J. G. Ray and H. J. Blom, "Vitamin B12 insufficiency and the risk of fetal neural tube defects," QJM, vol. 96, no. 4, pp. 289295, 2003.

[53] L. Suarez, K. Hendricks, M. Felkner, and E. Gunter, "Maternal serum B12 levels and risk for neural tube defects in a TexasMexico border population," Annals of Epidemiology, vol. 13, no. 2, pp. 81-88, 2003.

[54] J. G. Ray, P. R. Wyatt, M. D. Thompson et al., "Vitamin B12 and the risk of neural tube defects in a folic-acid-fortified population," Epidemiology, vol. 18, no. 3, pp. 362-366, 2007.

[55] P. N. Kirke, A. M. Molloy, L. E. Daly, H. Burke, D. G. Weir, and J. M. Scott, "Maternal plasma folate and vitamin B12 are independent risk factors for neural tube defects," Quarterly Journal of Medicine, vol. 86, no. 11, pp. 703-708, 1993.

[56] A. M. Molloy, P. N. Kirke, J. F. Troendle et al., "Maternal vitamin B12 status and risk of neural tube defects in a population with high neural tube defect prevalence and no folic acid fortification," Pediatrics, vol. 123, no. 3, pp. 917-923, 2009.

[57] T. Zhang, R. Xin, X. Gu et al., "Maternal serum vitamin B12, folate and homocysteine and the risk of neural tube defects in the offspring in a high-risk area of China," Public Health Nutrition, vol. 12, no. 5, pp. 680-686, 2009.

[58] (IOM), I.o.M.a.C., Dietary Reference Intake: Folate, Other B Vitamins and Choline, National Academy Press, Washington, DC, USA, 1998.

[59] Association générations futures A, r.e.A.e.s.H., WWF-France, Menus toxiques-Enquete sur les substances chimiques presentes dans notre alimentation: campagne "Environnement cancer", 2010.

[60] Narbonne, Sang pour sang toxique, 2010.

[61] Environmental Working Group, "The Pollution in Newborns: A benchmark investigation of industrial chemicals, pollutants and pesticides in umbilical cord blood," edited by B. Burden, 2005.

[62] WHO, "Malformations congénitales," in Soixante-Troiseeéme Assemblée Mondiale de la Santé, World Health Organization, Geneva, Switzerland, 2010.

[63] P. S. Shah and A. Ohlsson, "Effects of prenatal multimicronutrient supplementation on pregnancy outcomes: a metaanalysis," Canadian Medical Association Journal, vol. 180, no. 12, pp. E99-E108, 2009.

[64] L. Zeng, Y. Cheng, S. Dang et al., "Impact of micronutrient supplementation during pregnancy on birth weight, duration of gestation, and perinatal mortality in rural western China: double blind cluster randomised controlled trial," British Medical Journal, vol. 337, article a2001, 2008.

[65] G. Chen, X. Song, Y. Ji et al., "Prevention of NTDs with periconceptional multivitamin supplementation containing folic acid in China," Birth Defects Research Part A, vol. 82, no. 8, pp. 592-596, 2008.

[66] H. Blencowe, S. Cousens, B. Modell, and J. Lawn, "Folic acid to reduce neonatal mortality from neural tube disorders," International Journal of Epidemiology, vol. 39, pp. i110-121, 2010. 
[67] R. J. Berry, L. Bailey, J. Mulinare, and C. Bower, "Fortification of flour with folic acid," Food and Nutrition Bulletin, vol. 31, no. 1, pp. S22-S35, 2010.

[68] N. S. Adzick, E. A. Thom, C. Y. Spong et al., "A randomized trial of prenatal versus postnatal repair of myelomeningocele," New England Journal of Medicine, vol. 364, no. 11, pp. 9931004, 2011.

[69] Force, U.S.P.S.T., "Folic acid for the prevention of neural tube defects: U.S. Preventive services task force recommendation statement," Annals of Internal Medicine, vol. 150, no. 9, pp. 626-631, 2009.

[70] G. Maberly, L. Grummer-Strawn, M. E. Jefferds et al., "Trends in wheat-flour fortification with folic acid and ironworldwide, 2004 and 2007," Morbidity and Mortality Weekly Report, vol. 57, no. 1, pp. 8-10, 2008.

[71] National Birth Defects Prevention Network, "Neural tube defect ascertainment project 2010," 2010.

[72] B. Khoshnood, R. Greenlees, M. Loane, and H. Dolk, "Paper 2: EUROCAT public health indicators for congenital anomalies in Europe," Birth Defects Research Part A, vol. 91, no. 1, pp. S16-S22, 2011.

[73] Prevention, C.f.D.C.a., "Effectiveness in disease and injury prevention use of folic acid for prevention of spina bifida and other neural tube defects-1983-1991," Morbidity and Mortality Weekly Report, vol. 41, pp. 513-516, 1992.

[74] K. N. Bell and G. P. Oakley Jr., "Update on prevention of folic acid-preventable spina bifida and anencephaly," Birth Defects Research Part A, vol. 85, no. 1, pp. 102-107, 2009.

[75] S. G. Običan, R. H. Finnell, J. L. Mills, G. M. Shaw, and A. R. Scialli, "Folic acid in early pregnancy: a public health success story," FASEB Journal, vol. 24, no. 11, pp. 4167-4174, 2010.

[76] B. S. Mosley, M. A. Cleves, A. M. Siega-Riz et al., "Neural tube defects and maternal folate intake among pregnancies conceived after folic acid fortification in the United States," American Journal of Epidemiology, vol. 169, no. 1, pp. 9-17, 2009.

[77] K. Ahrens, M. M. Yazdy, A. A. Mitchell, and M. M. Werler, "Folic acid intake and spina bifida in the era of dietary folic acid fortification," Epidemiology, vol. 22, no. 5, pp. 731-737, 2011.

[78] Y. Yi, M. Lindemann, A. Colligs, and C. Snowball, "Economic burden of neural tube defects and impact of prevention with folic acid: a literature review," European Journal of Pediatrics, vol. 170, no. 11, pp. 1391-1400, 2011.

[79] J. P. Bruner, W. O. Richards, N. B. Tulipan, and T. L. Arney, "Endoscopic coverage of fetal myelomeningocele in utero," American Journal of Obstetrics and Gynecology, vol. 180, no. 1 I, pp. 153-158, 1999.

[80] N. Tulipan and J. P. Bruner, "Myelomeningocele repair in utero: a report of three cases," Pediatric Neurosurgery, vol. 28, no. 4, pp. 177-180, 1998.

[81] N. S. Adzick, L. N. Sutton, T. M. Crombleholme, and A. W. Flake, "Successful fetal surgery for spina bifida," Lancet, vol. 352, no. 9141, pp. 1675-1676, 1998.

[82] N. S. Adzick, "Fetal myelomeningocele: natural history, pathophysiology, and in-utero intervention," Seminars in Fetal and Neonatal Medicine, vol. 15, no. 1, pp. 9-14, 2010. 


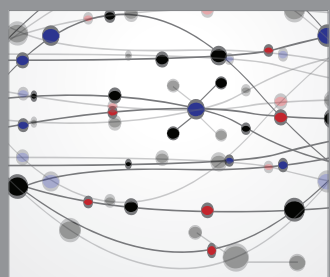

The Scientific World Journal
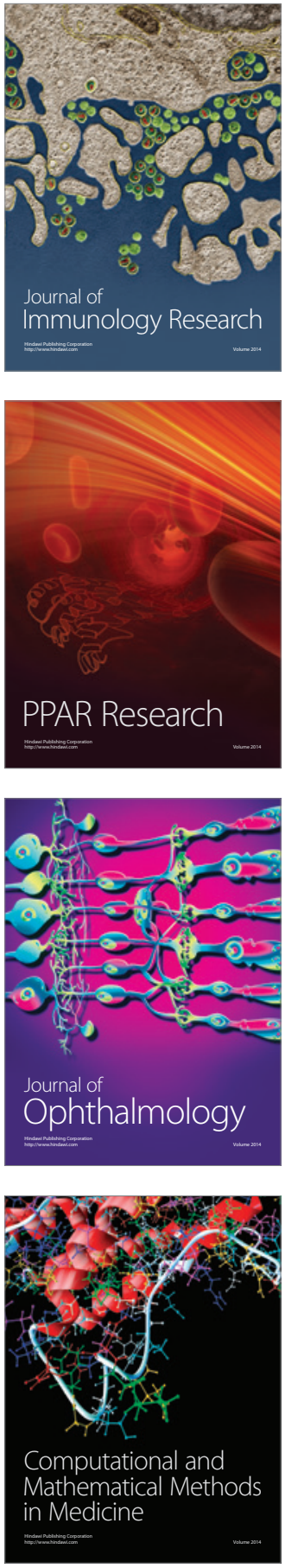

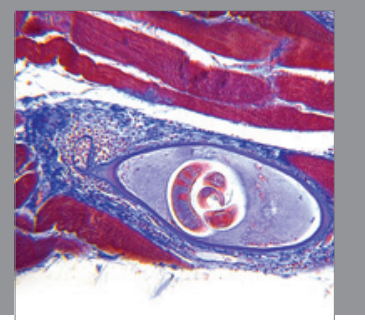

Gastroenterology

Research and Practice
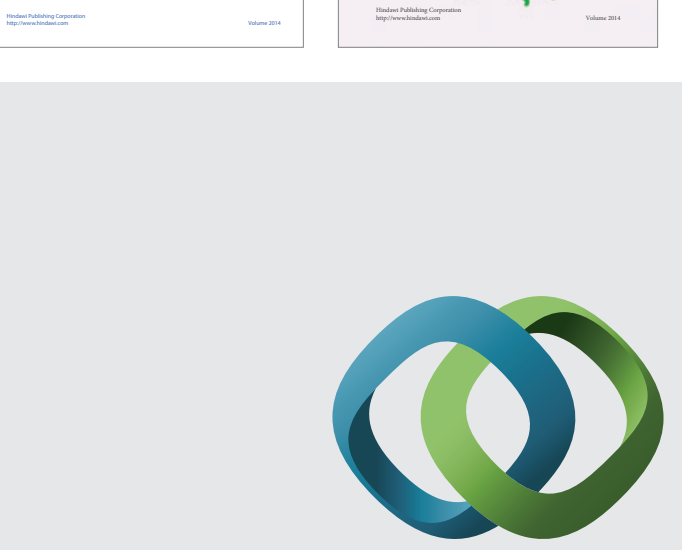

\section{Hindawi}

Submit your manuscripts at

http://www.hindawi.com
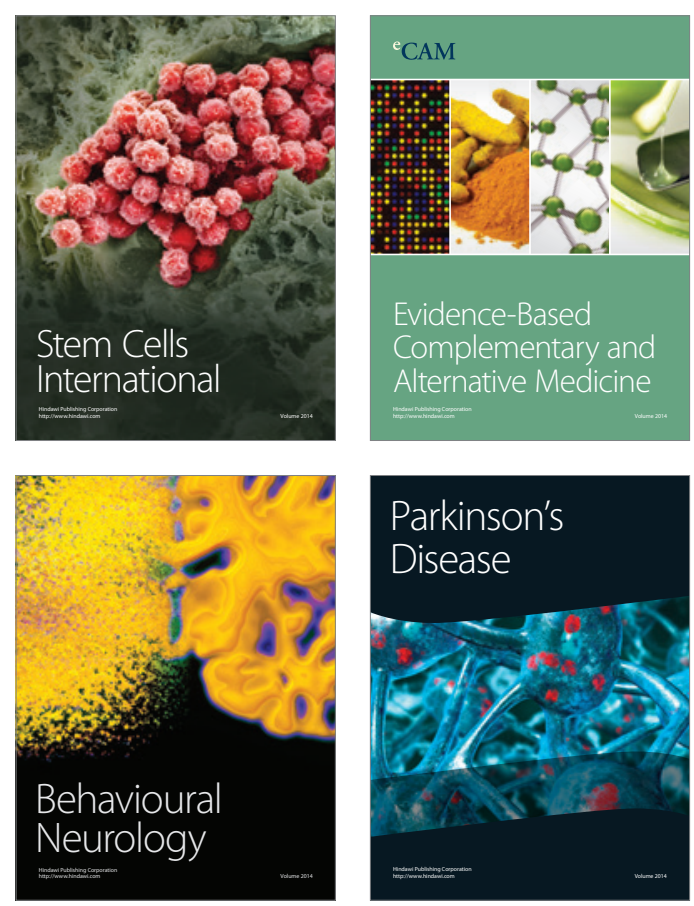

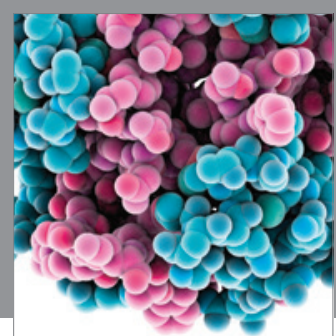

Journal of
Diabetes Research

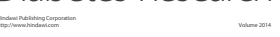

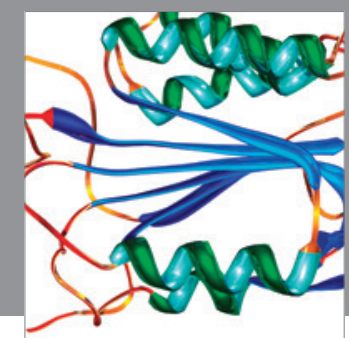

Disease Markers
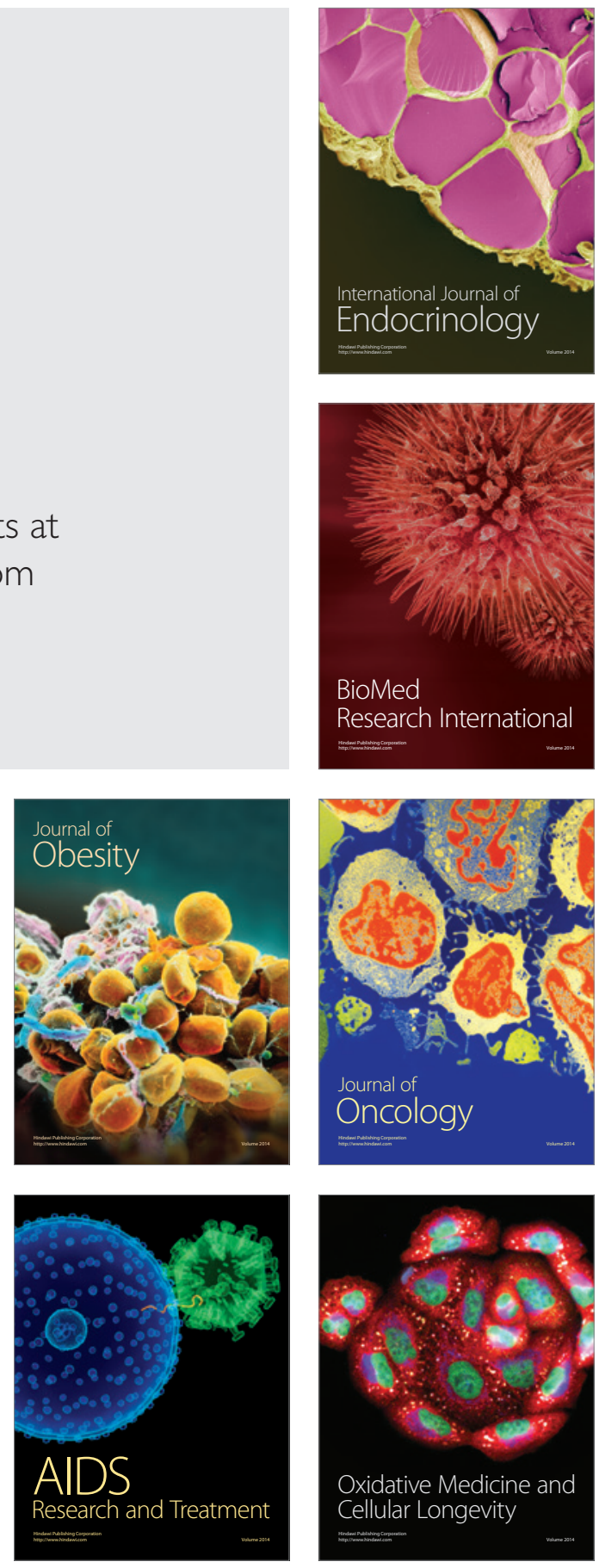